\title{
Autoeficácia em Professores do Ensino Superior
}

\author{
The Self-Efficacy for Professors
}

\author{
José Ricardo Claudino Ribeiro*a; Camila Cristina Fonseca Bicalho ${ }^{\mathrm{b}}$; Marcos Teixeira de Abreu Soares Onofree Franco Noc $^{\mathrm{b}}$ \\ ${ }^{a}$ Minas Tênis Clube. MG, Brasil.

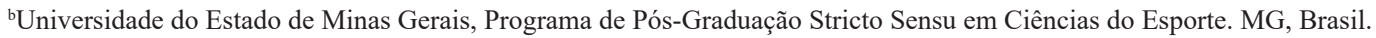 \\ 'Universidade Técnica de Lisboa. Lisboa, Portugal. \\ *Email: jose.ricardo@minastc.com.br. \\ Recebido em: 29/04/19; Aceito em: 02/09/19
}

\begin{abstract}
Resumo
O objetivo deste estudo foi avaliar a percepção de autoeficácia em professores do Ensino Superior e avaliar as propriedades psicométricas da Escala de Autoeficácia para Professores do Ensino Superior para o contexto brasileiro. Participaram deste estudo 188 professores do Ensino Superior de instituições da rede privada de Minas Gerais. Os professores lecionavam nas áreas da Educação Física, Nutrição, Ciências Biológicas, Geografia, Fisioterapia, Medicina, Análise de Sistemas, Enfermagem, Turismo e Pedagogia. A amostra foi composta por 61,5\% de professores do sexo masculino. Em relação à formação, foi predominante a participação de professores com especialização Lato Sensu (52,9\%). Todos os professores responderam a Escala de Autoeficácia para Docentes do Ensino Superior-EADES. Os resultados mostraram que a escala está adequada para a avaliação da autoeficácia em professores $(\alpha=0,92)$. Em relação ao quanto os professores se sentem capazes de realizar suas tarefas docentes, foram verificados valores médios entre 5,01 e 5,65, o que representa um alto valor de percepção de autoeficácia pelos professores. Conclui-se que os principais fatores responsáveis pela autoeficácia dos professores são a Satisfação, a Persuasão Social e as Experiências Pregressas. Estes aspectos fornecem uma importante sugestão sobre as possibilidades de exploração destes fatores no que diz respeito às futuras aquisições, programas de formação e pesquisas futuras.
\end{abstract}

Palavras-chave: Validação. Eficácia Docente. Educação Superior.

\begin{abstract}
The aim of this study was to evaluate the perception of self-efficacy in higher education teachers and to evaluate the psychometric properties of the Self-efficacy Scale for higher education teachers in the Brazilian context. A total of 188 higher education teachers from institutions of the private network of Minas Gerais participated in this study. Teachers taught in the areas of Physical Education, Nutrition, Biological Sciences, Geography, Physiotherapy, Medicine, Systems Analysis, Nursing, Tourism and Pedagogy. The sample consisted of 61.5\% male teachers. All teachers answered the Self-Efficacy Scale for Teachers of Higher Education-EADES. Lato Sensu teachers (52.9\%), followed by master teachers (34.8\%), doctors (9.6\%) and graduates (2.7\%) predominated. The results showed that the scale is adequate for the evaluation of selfefficacy in teachers $(\alpha=0.92)$. In relation to how much teachers feel capable of performing their teaching tasks, mean values between 5.01 and 5.65 were verified, which represents a high value of self-efficacy perception among teachers. It is concluded that the main factors responsible for teachers'self-efficacy are satisfaction, social persuasion and previous experiences. These aspects provide an important suggestion about the possibilities of exploring these factors with regard to future acquisitions, training programs and future research.
\end{abstract}

Keywords: Validation. Professor Efficacy. University Education.

\section{Introdução}

Com os avanços tecnológicos, a sociedade contemporânea mais do que nunca parece estar na era da informação. Contudo, os processos cognitivos relacionados a este aspecto, que são as ações de aquisição, organização e uso da informação, parecem ser regulados pelos processos afetivos. Estes processos influenciam os níveis de motivação, condicionando as escolhas e a intensidade dos esforços, todavia, o exercício destes processos (auto regulação das ações ou aprendizagens) dependem das percepções de autoeficácia do professor (SILVA et al., 2018).

A Teoria da Autoeficácia, apresentada Bandura (1977), propõe uma das variáveis cognitivas com funções motivacionais mais promissoras dos últimos anos, seja na promoção da saúde, na profilaxia de doenças (ACSM, 2000) ou no próprio cotidiano das pessoas (ARAÚJO et al., 2009). A autoeficácia refere-se ao juízo individual de quanto são capazes de organizar e implementar atividades, em situações variadas e desconhecidas, passíveis de conter elementos geradores de estresse. Pereira et al. (2007) analisaram os trabalhos publicados entre os anos de 1977 a 2004 e observaram que neste período houve uma evolução quantitativa até a segunda metade da década de 90 sobre estudos voltados para avaliar a autoeficácia do professor. Avalia-se que as pesquisas com essa temática foram regredindo quantitativamente após a década de 90 até os dias de hoje. Uma explicação possível para este comportamento se decorre em função da consolidação da Teoria Social Cognitiva ao longo destes anos.

A Teoria Social Cognitiva foi proposta por Bandura (1977). Nela, o homem é um ser em constantes mudanças, sendo ele 
o principal personagem deste processo, agente da sua própria transformação. Neste sentido, a percepção de autoeficácia pode ser definida como o sentimento sobre a capacidade que o ser humano possui de executar determinadas tarefas, vista por ele mesmo (BANDURA, 2005). Segundo Nascimento (1999), estas percepções são dinâmicas e dependentes da percepção de sucessos e fracassos anteriores, bem como da capacidade de auto avaliação e exercem influência direta nas estratégias para a resolução dos problemas, sejam eles de ordem pessoal ou profissional. Assim, a auto regulação pode ser entendida como uma importante qualidade do homem na sociedade moderna (POLYDORO; AZZI, 2008).

Em estudo apresentado por Souza e Mendonça (2009), ser professor foi a segunda profissão mais influenciada pela exaustão emocional, influenciada pela baixa percepção de eficácia. Reinhold (2007) afirma que os docentes estão sujeitos a fatores estressantes resultantes do exercício profissional expondo-se ao desenvolvimento de reações de estresse em diversos níveis, com indícios de depressão, exaustão, raiva e traços psicossomáticos. Afirma-se também que professores com menos tempo de carreira, com pouca experiência, podem acabar se frustrando com expectativas irrealistas da profissão (ANDRADE et al., 2017). Tais situações refletem diretamente na sensação de incompetência e a falta de produção no trabalho, no qual a percepção de autoeficácia pode ser um fator que contribui para o sentimento de satisfação profissional.

É imprescindível considerar o professor como um profissional que adquire e desenvolve conhecimentos a partir da prática e no confronto com as condições da profissão. Nesse contexto, a percepção da sua própria eficácia deve exercer um importante papel na qualidade das suas intervenções. Isto foi verificado em uma reanálise, que considerou 36 estudos entre os anos de 1977 e 1988, citada por Bzuneck (2009), em que a correlação entre a crença de autoeficácia e o desempenho variou entre 0,38 e 0,70. Em se tratando do Ensino Superior, esta necessidade não é diferente. Estudos como o de Martins et al. (2006), onde foram analisadas as percepções de competências profissionais em relação à área de graduação, frequência em eventos científicos, carga-horária semanal de trabalho e suas afinidades com as instituições onde trabalham, já apontam para a crescente necessidade e preocupação de se investigar e entender os mecanismos que norteiam a percepção de autoeficácia profissional, as bases teóricas que sustentam seus conceitos, suas aplicabilidades, bem como a validade dos instrumentos que se propõe mensurar este fenômeno.

Assim, esse estudo tem como objetivo avaliar a percepção de autoeficácia de professores do Ensino Superior, bem como propor uma avaliação das propriedades psicométricas da Escala de Autoeficácia para Professores do Ensino Superior frente à realidade brasileira.

\section{Material e Métodos}

Participaram deste estudo 188 professores do Ensino Superior de instituições da rede privada de Minas Gerais com idade média de 40 anos ( $\pm 8,6$ anos). Os professores lecionavam nos cursos de graduação das áreas da Educação Física, Nutrição, Ciências Biológicas, Geografia, Fisioterapia, Medicina, Análise de Sistemas, Enfermagem, Turismo e Pedagogia. Ao total, 116 (61,5\%) professores eram do sexo masculino e $72(38,5 \%)$ eram professoras do sexo feminino. Em relação à formação, predominaram os professores especialistas (pós-graduados Lato Sensu), compondo mais da metade da amostra $(52,9 \%)$, mestres $(34,8 \%)$, doutores $(9,6 \%)$, e graduados $(2,7 \%)$.

A Escala de Autoeficácia para Docentes do Ensino Superior-EADES (PRIETO, 2005) foi selecionada para este estudo, por avaliar a percepção de autoeficácia dos professores do Ensino Superior, nas dimensões básicas da docência. $\mathrm{O}$ referido instrumento foi proposto em função da necessidade de se obter maiores informações sobre a influência das crenças dos professores universitários nas suas práticas pedagógicas. Fato este que, na visão de especialistas, pode reduzir a eficácia profissional (PRIETO, 2005). Além disso, permite verificar a relação do tempo de docência com as percepções de autoeficácia dos professores e necessita de avaliação de suas características psicométricas no Brasil

O EADES apresentou um bom coeficiente de confiabilidade $(\alpha=0,94)$ e foi desenvolvido em três blocos, agrupados em: Blocos 1: Atividades relacionadas à docência; Bloco 2: Sobre a instituição que o professor trabalha; e Bloco 3: Relacionado às reflexões do próprio professor (PRIETO, 2005). O instrumento utiliza a escala tipo Likert, quantificada de "1" a "6", solicitando aos indivíduos que preencham a escala em função de quatro possibilidades de continuum: "O quanto me sinto capaz de..."; "Com que frequência costumo..."; "Totalmente Falso/Totalmente Verdadeiro"; e "Desacordo Total/Concordância Total". Os escores de autoeficácia foram calculados pela média aritmética simples, considerando a escala de 1 a 6 . Dentre as opções de preenchimento das escalas, verificou-se que a inquirição "Com que frequência costumo..." foi a única que extrapola a auto percepção e direciona para uma condição de comportamento momentâneo, que não necessariamente estará influenciada pela autoeficácia. Em função disto, na atual versão da escala essa dimensão não será analisada de forma específica.

Os questionários foram entregues na secretaria das instituições, com as devidas instruções sobre os aspectos éticos e os objetivos do trabalho, evitando o que Bandura (2005) alerta como comprometimento dos dados, quando uma escala de autoeficácia é aplicada sem uma abordagem prévia sobre a relevância social, os objetivos do estudo e a garantia de sigilo. Quanto ao problema em potencial da 
fadiga mental no preenchimento do instrumento (BABBIE, 1999), foi adotado a estratégia de randomizar os blocos de perguntas, de forma que a amostra não tendesse comprometer a qualidade das respostas dos mesmos (últimos) blocos de perguntas.

Este trabalho foi desenvolvido a partir de uma técnica operacional de mobilização dos docentes de duas instituições de Ensino Superior, adotando a seguinte estratégia: Inicialmente os coordenadores dos cursos das instituições foram contatados, foram esclarecidos quanto ao objetivo e justificativa do estudo e enviaram aos seus respectivos professores uma mensagem (redigida pelo próprio autor do trabalho) sugerindo a participação ativa no trabalho. O autor disponibilizou em todos as caixas de materiais pessoais dos professores um documento que continha as vias do Termo de Consentimento Livre e Esclarecido (TCLE), uma abordagem sobre os objetivos, justificativas e benefícios do estudo e uma cópia autoexplicativa da escala a ser preenchida.

O processo de tradução e adaptação cultural do referido instrumento obedeceu às recomendações de Both et al. (2006); Mendonça e Guerra (2007); Pasquali (1999; 2003) e Thomas et al. (2007) e consistiu nas seguintes fases: Fase 1: Tradução do instrumento para o Português; Fase 2: Tradução da versão para o idioma original (back-translation). Vale ressaltar que a terminologia dos dois idiomas é extremamente semelhante, exigindo poucos ajustes ou divergências de procedimentos, entretanto, toda a etapa foi cumprida de forma normativa; Fase 3: Avaliação por um júri de peritos objetivando ajustar a terminologia e promover a adequação semântica e conceitual para adequar as questões em suas reais dimensões (também denominada Validação Ecológica). Para tal processo, os itens da escala foram submetidos à análise da adequação semântica e conceitual por cinco peritos nas áreas de pedagogia (2), didática (1) e psicologia (2) e, posteriormente, após uma entrevista e a retificação dos itens que receberam três ou mais sugestões de alterações convergentes (BOTH et al., 2006), assumindo como sendo o ponto de corte, conforme sugerido por Sperber (2004); e Fase 4: Pré-teste da versão final, culminando na avaliação da carga fatorial e proposta do instrumento, conforme estrutura apresentada na Figura 1:

Figura 1 - Passos metodológicos do estudo.

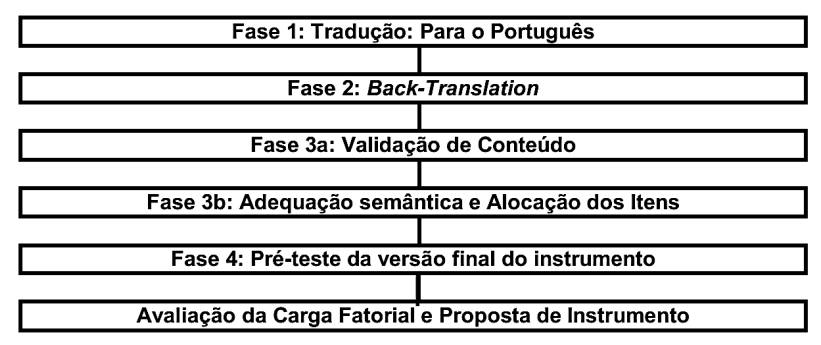

Fonte: Os autores.
Apesar de não ter sido verificado problemas interpretativos nos itens da escala, houve dificuldade de entendimento dos parâmetros usados no primeiro bloco de itens (em função da duplicidade de avaliação dos itens), o que nos fez alertar os voluntários da pesquisa sobre a necessidade de se preencher cada bloco, integralmente, por vez.

Para o tratamento dos dados utilizou-se o programa estatístico SPSS 21.0 para Windows ${ }^{\circledR}$. Utilizou-se a estatística descritiva para apresentação das principais características dos voluntários. Para comparar a percepção de autoeficácia dos docentes em função do tempo de docência foi utilizada a estatística de teste de Mann Whitney, por se tratar de dois grupos, não emparelhados, e serem dados escalares (DANCEY; REIDY, 2007). Para testar a validade de constructo e promover a confirmação de uma estrutura fatorial foi utilizado o procedimento estatístico de Análise de Componentes Principais, que foi antecedida ao teste de esfericidade de Bartlet. Foram analisadas as características da matriz de correlação inter-itens, utilizando-se o índice de KMO (Kaiser-Meyer-Olkin) para verificar as características das correlações parciais inter-itens e o Teste de Esfericidade de Bartlett para testar a identidade da matriz (de todo o instrumento analisado). O KMO superior a 0,50 e o teste de esfericidade de Bartlett apresentando significância $(p \leq 0,05)$, implica que a análise fatorial é adequada para este conjunto de dados (HAIR et al., 2003).

\section{Resultados e Discussão}

Dos 464 questionários enviados, 188 (40,5\%) foram recebidos, devidamente preenchidos. Os resultados sobre a percepção da autoeficácia foram apresentados de acordo com os blocos do EADES, abordando aspectos tais como o quanto os professores se sentem capazes de realizar suas tarefas docentes. Paralelamente, foi estabelecida uma abordagem analítica sobre a correlação entre "o quanto os professores se sentem capazes" e "com qual frequência eles aplicam", bem como a análise das principais fontes de autoeficácia percebidas pelos professores. O gráfico da Figura 2 apresenta a pontuação média de cada item da escala, podendo variar entre um a seis pontos por item. 
Figura 2 - Valores médios da frequência de respostas para cada item da EADES.

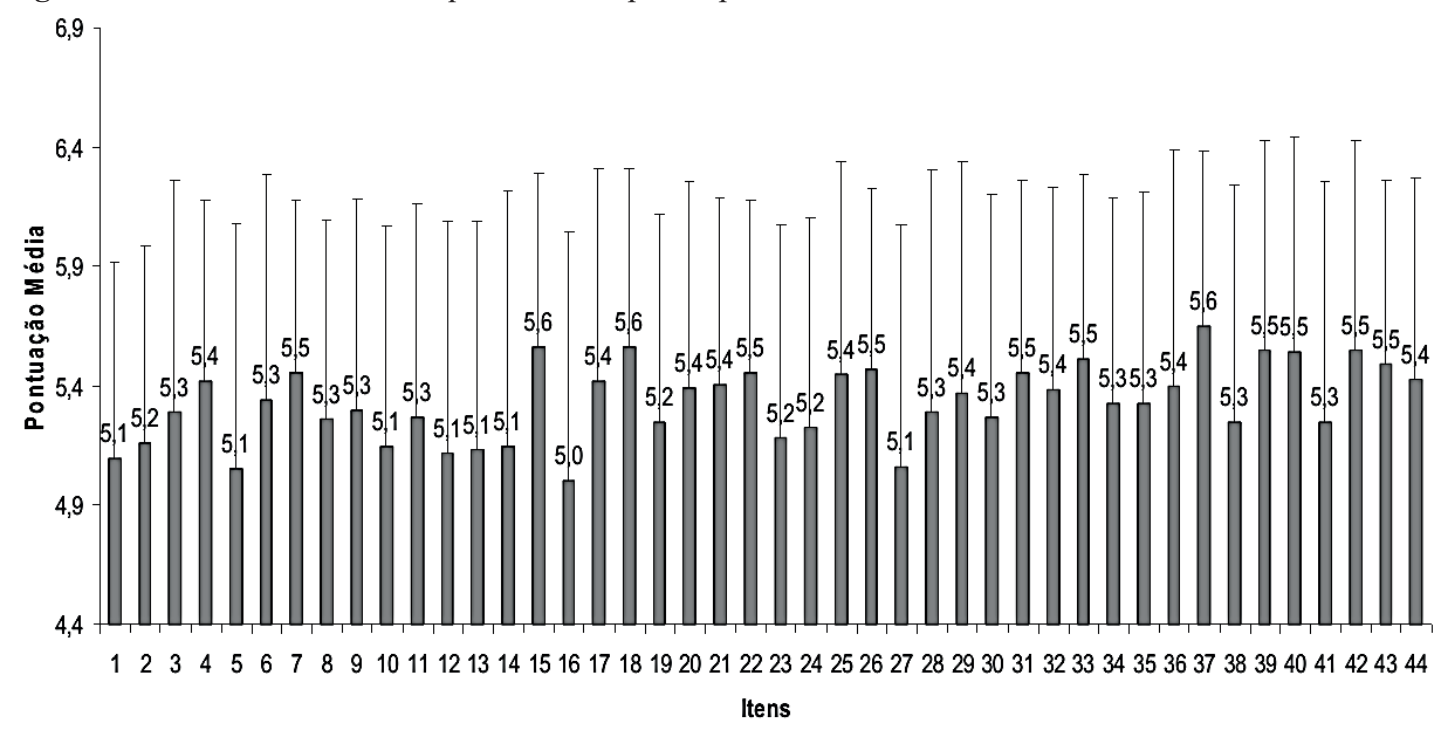

Fonte: Dados da pesquisa.

Em relação ao quanto os professores se sentem capazes de realizar suas tarefas docentes, $\mathrm{o}$ instrumento original relata valores entre 3,96 e 5,57, sendo mais ampla quando os itens se relacionam aos aspectos de estratégias didáticas. Prieto (2005) sugere que as atividades que envolvem a planificação e interação com os alunos são fatores muito positivos na percepção de autoeficácia dos professores, se opondo, por exemplo, aos procedimentos avaliativos. Nesse estudo foram verificados valores médios entre 5,01 e 5,65, com coeficientes de variação entre 13 e $21 \%$, indicando boa percepção de autoeficácia.

O presente estudo refutou a hipótese levantada por Prieto (2005), de que as competências docentes podem se diferenciar conforme as áreas de atuação. Os valores dos Coeficientes de Variação apresentados na amostra avaliada (entre 13 e 21\%) e a diversidade de áreas estudadas não parecem apresentar indicativos deste comportamento. Os valores de Coeficiente de Variação abaixo de 25\% sugerem que, para esta amostra, os diferentes cursos não influenciaram de forma expressiva a homogeneidade dos resultados.

O resultado da análise de correlação apresentado no Quadro 1 entre "o quanto os professores se sentem capazes" com "qual a frequência que eles aplicam", mostrou que dos 44 itens, apenas os itens "10", "11", "20", " 21 ”, " 22 " e " 25 " não apresentaram valores de correlação significativos. Todos os demais (35 itens) confirmaram os achados de Prieto (2005), revelando uma clara relação entre o que os professores se sentem capazes de realizar com o que eles de fato realizam ou praticam.

Quadro 1 - Resultado da análise de correlação entre "o quanto os professores se sentem capazes" com "qual a frequência que eles aplicam"

\begin{tabular}{|c|c|c|c|c|c|c|c|c|c|c|c|c|c|c|c|}
\hline Itens & $\mathbf{1}$ & $\mathbf{2}$ & $\mathbf{3}$ & $\mathbf{4}$ & $\mathbf{5}$ & $\mathbf{6}$ & $\mathbf{7}$ & $\mathbf{8}$ & $\mathbf{9}$ & $\mathbf{1 0}$ & $\mathbf{1 1}$ & $\mathbf{1 2}$ & $\mathbf{1 3}$ & $\mathbf{1 4}$ & $\mathbf{1 5}$ \\
\hline Média & 5,1 & 5,2 & 5,3 & 5,4 & 5,1 & 5,3 & 5,5 & 5,3 & 5,3 & 5,1 & 5,3 & 5,1 & 5,1 & 5,1 & 5,6 \\
\hline DP & 0,82 & 0,83 & 1 & 0,8 & 1 & 0,9 & 0,7 & 0,8 & 0,9 & 0,9 & 0,9 & 1 & 1 & 1,1 & 0,7 \\
\hline Correlações & 0,45 & 0,31 & 0,45 & 0,45 & 0,41 & 0,44 & 0,23 & 0,35 & 0,35 & 0,17 & 0,16 & 0,22 & 0,32 & 0,40 & 0,33 \\
\hline Itens & 16 & 17 & 18 & 19 & 20 & 21 & 22 & 23 & 24 & 25 & 26 & 27 & 28 & 29 & 30 \\
\hline Média & 5,0 & 5,4 & 5,6 & 5,2 & 5,4 & 5,4 & 5,5 & 5,2 & 5,2 & 5,4 & 5,5 & 5,1 & 5,3 & 5,4 & 5,3 \\
\hline DP & 1 & 0,9 & 0,8 & 0,9 & 0,9 & 0,8 & 0,7 & 0,9 & 0,9 & 0,9 & 0,8 & 1 & 1 & 1 & 0,9 \\
\hline Correlações & 0,46 & 0,32 & 0,29 & 0,23 & 0,01 & 0,15 & 0,11 & 0,26 & 0,23 & 0,14 & 0,25 & 0,35 & 0,32 & 0,32 & 0,38 \\
\hline Itens & 31 & 32 & 33 & 34 & 35 & 36 & 37 & 38 & 39 & 40 & 41 & 42 & 43 & 44 & \\
\hline Média & 5,5 & 5,4 & 5,5 & 5,3 & 5,3 & 5,4 & 5,6 & 5,3 & 5,5 & 5,5 & 5,3 & 5,5 & 5,5 & 5,4 & \\
\hline DP & 0,8 & 0,8 & 0,8 & 0,9 & 0,9 & 1 & 0,7 & 1 & 0,9 & 0,9 & 1 & 0,9 & 0,8 & 0,8 & \\
\hline Correlações & 0,43 & 0,25 & 0,34 & 0,38 & 0,40 & 0,27 & 0,22 & 0,27 & 0,35 & 0,24 & 0,26 & 0,21 & 0,40 & 0,20 & \\
\hline
\end{tabular}

Fonte: Dados da pesquisa. 
Ao analisar as principais fontes de autoeficácia percebidas pelos professores (Figura 3), foi verificado por Prieto (2005) que os itens " 8 ", "5" e "10", se apresentaram como as maiores responsáveis por tal desenvolvimento. Estes resultados permitiram a autora inferir que a satisfação, a experiência e os livros e revistas especializadas, são as principais responsáveis pela autoeficácia dos professores. Já no Brasil, nesta pesquisa, os fatores que apresentaram maiores níveis de influência estão relacionados aos itens "14", “7”, "8" e “1", revelando que, para os docentes, a satisfação (14 e 8), a persuasão social (7) e as experiências pregressas (1), são os principais responsáveis pela percepção de autoeficácia dos professores.

Figura 3 - Distribuição média da frequência de respostas para cada item do bloco 2 e bloco 3 do EADES, respectivamente


Fonte: Dados da pesquisa.

Em diversos estudos a experiência e a titulação dos professores apresentaram uma relação direta e significativa com a percepção de autoeficácia (PRIETO 2005; SILVA 2014; SILVA et al., 2017; SILVA et al., 2018). Neste estudo os resultados mostraram diferenças significativas $(\mathrm{p} \leq 0,05)$ nos itens “19”, “27”, “33”, “36”, “37” e “41” no Bloco 1 "O quanto me sinto capaz"; no item " 27 " do Bloco 1 "Com que frequência aplico"; no item "6" do Bloco "2" e no item "7" do Bloco "3”. Quanto ao nível de preparação percebida pelos professores (ou a percepção de autoeficácia) e o tempo de docência, Prieto (2005) verificou que quanto mais experiente era o docente, maior era a percepção de autoeficácia. Estes achados não foram verificados nesta amostra, bem como no estudo de Silva et al. (2008). Apesar de haver uma tendência natural deste tipo de comportamento (BZUNECK; GUIMARÃES, 2009), o percentual de docentes que atingem o critério temporal de classificação de perito (MORAES et al.,
1999) foi de 12,8\%. Apenas os itens “4”, “34”, “36” e “38” apresentaram diferença significativa $(\mathrm{p} \leq 0,05)$.

A titulação dos docentes não se mostrou muito interveniente nas percepções de autoeficácia dos voluntários desta pesquisa, entretanto, o tempo de docência apresentou correlação significativa na maioria dos itens da escala original.

\subsection{Análise e validação preliminar do EADES em uma amostra de professores brasileiros}

O resultado do teste KMO e o Teste de Esfericidade de Bartlett indicaram significância para cada bloco, com os respectivos valores: bloco 10,75 ; bloco 2 0,77; bloco 30,55 . Quando estes testes apresentam valores maiores que 0,50 revelam que o conjunto de dados apresenta significância $(\mathrm{p} \leq 0,05)$ e implica que a análise fatorial é adequada.

Para verificação da consistência interna das dimensões foi utilizado índice Alfa de Cronbach (CRONBACH, 1951) apresentando o valor para a escala de $\alpha=0,92$. No Quadro 2 há uma síntese dos resultados das cargas fatoriais associadas às tendências semânticas dos itens do bloco 1. Para o bloco 1 foi identificado o valor de $\alpha=0,90$.

Quadro 2 - Distribuição da carga fatorial dos itens do EADES versão brasileira

\begin{tabular}{|c|c|c|c|c|}
\hline & \multicolumn{5}{|c|}{ Fatores } \\
\hline & $\mathbf{1}$ & $\mathbf{2}$ & $\mathbf{3}$ & $\mathbf{4}$ \\
\hline B1 E1 & 0,349 & & & \\
\hline B1 E2 & 0,568 & & & \\
\hline B1 E5 & 0,578 & & & \\
\hline B1 E8 & 0,593 & & & \\
\hline B1 E10 & 0,446 & & & \\
\hline B1 E12 & 0,305 & & & \\
\hline B1_E13 & 0,627 & & & \\
\hline B1 E15 & 0,446 & & & \\
\hline B1 E17 & 0,329 & & & \\
\hline B1 E28 & 0,500 & & & \\
\hline B1 E31 & 0,513 & & & \\
\hline B1 E18. & & & & \\
\hline B1 E35. & & 0,523 & & \\
\hline B1 E39 & & 0,603 & & \\
\hline B1 E40 & & 0,480 & & \\
\hline B1 E43 & & 0,533 & & \\
\hline B1 E44. & & 0,513 & & \\
\hline B1 E16. & & & 0,430 & \\
\hline B1 E19. & & & 0,575 & \\
\hline B1 E21. & & & 0,505 & \\
\hline B1 E24 & & & 0,635 & \\
\hline B1 E25 & & & 0,516 & \\
\hline B1 E26 & & & 0,370 & \\
\hline B1 E27 & & & 0,685 & \\
\hline B1 E33. & & & 0,534 & \\
\hline B1 E34 & & & 0,323 & \\
\hline B1 E37. & & & 0,306 & \\
\hline B1 E42 & & & 0,421 & \\
\hline B1 E4 & & & & 0,384 \\
\hline B1 E6 & & & & \\
\hline B1 E7. & & & & \\
\hline B1 E29 & & & & \\
\hline B1 E32 & & & & \\
\hline B1 E36 & & & & \\
\hline B1 E38. & & & & \\
\hline B1 E41. & & & & \\
\hline
\end{tabular}

Fonte: Dados da pesquisa. 
Referente ao conteúdo de cada item, foram atribuídos conceitos aos fatores. O fator "A" (itens 1, 2, 4, 7, 8, 9, 10, 11, $13,19,22$, e 24) aborda os aspectos relacionados ao processo de aprendizagem e dos processos avaliativos. Conforme visualizado no Quadro 3, em todos os itens há uma tendência de se considerar aspectos da aprendizagem e de avaliação. O fator "B" (itens 14, 28, 32, 33, 36) se relaciona com o conteúdo programático a ser desenvolvido, bem como os recursos didáticos utilizados. $\mathrm{O}$ fator " $\mathrm{C}$ " (itens 12, 15, 16, $17,18,20,21,26,27,30,35)$ traz como principais aspectos o desempenho na docência, com foco nos alunos. O fator " $D$ " (itens 3, 5, 6, 23, 25, 29,31,34) fornece informações sobre o processo de auto avaliação e à relação interpessoal com os alunos. Para a versão final do EADES -bloco1, os itens 3, 9, 11, 20 e 30, apesar de apresentarem cargas fatoriais relativamente altas, não foram alocados em função da incompatibilidade semântica. Já os itens 22 e 23, não foram alocados em função do grande equilíbrio em três dos quatro fatores. Como todos os fatores já estavam suficientemente cercados por outros itens (mais definidos), optou-se por excluir estes dois.

Quadro 3 - Proposta final da escala do Bloco 1- "O quanto me sinto capaz"

\begin{tabular}{|c|c|}
\hline Itens & Fator \\
\hline Especificar os objetivos de aprendizagem que espero que os alunos atinjam. & $\mathbf{A}$ \\
\hline Mobilizar ativamente os alunos nas atividades de aprendizagem que proponho nas aulas. & $\mathbf{A}$ \\
\hline Rever a minha prática docente para identificar alguns aspectos a serem melhorados. & D \\
\hline Aplicar diferentes estratégias de avaliação, de acordo com os objetivos dos conteúdos previamente estabelecidos. & $\mathbf{A}$ \\
\hline Avaliar a efetividade do meu ensino levando em consideração o feedback dos alunos. & D \\
\hline Estimular a participação dos alunos nas aulas. & D \\
\hline Utilizar diversas estratégias de avaliação. & A \\
\hline Conseguir que os alunos se preocupem em resolver dificuldades que encontram ao longo da sua aprendizagem. & A \\
\hline Conduzir o processo ensino-aprendizagem com base nas avaliações dos meus alunos acerca da minha eficácia docente. & A \\
\hline Mapear, através da avaliação, como os alunos usam as diferentes capacidades (pensamento crítico, análise). & $\mathbf{A}$ \\
\hline Concentrar esforços para que os alunos se considerem capazes de aprender. & A \\
\hline Utilizar métodos sistemáticos que me permitam analisar a minha competência docente. & $\mathbf{C}$ \\
\hline Discutir com os alunos os resultados da sua avaliação. & A \\
\hline Identificar claramente os objetivos de cada aula. & B \\
\hline Manter, apesar das possíveis dificuldades, expectativas positivas em relação aos alunos. & $\mathbf{C}$ \\
\hline Analisar adequadamente os trabalhos/avaliações dos alunos & $\mathbf{C}$ \\
\hline Dar apoio e incentivo aos alunos que têm dificuldades de aprendizagem. & $\mathbf{C}$ \\
\hline Capacitar-me continuamente sobre os conteúdos das disciplinas que leciono. & $\mathrm{C}$ \\
\hline Manter, apesar das possíveis dificuldades, expectativas positivas em relação aos alunos & $\mathbf{A}$ \\
\hline Dar aos alunos, por meio da avaliação, uma informação detalhada acerca dos seus desempenhos & $\mathbf{C}$ \\
\hline Adequar a metodologia ao nível dos alunos. & $\mathbf{C}$ \\
\hline Propiciar que os alunos preparem e desenvolvam alguns conteúdos da disciplina. & A \\
\hline Lidar com a devida maturidade frente a possíveis problemas que possam surgir nas aulas. & $\mathbf{D}$ \\
\hline $\begin{array}{l}\text { Nas aulas, utilizar formas de avaliação, conceitos e fatos para obter alguma informação acerca da evolução do } \\
\text { processo de aprendizagem dos alunos. }\end{array}$ & $\mathbf{A}$ \\
\hline Estimular os alunos a formularem questões durante as aulas. & D \\
\hline Transmitir aos alunos que me preocupo pessoalmente com eles e com a suas aprendizagens. & $\mathbf{C}$ \\
\hline Avaliar se os objetivos de aprendizagem, previamente estabelecidos, foram alcançados. & $\mathbf{C}$ \\
\hline Programar a estrutura e o conteúdo de cada aula. & B \\
\hline $\begin{array}{l}\text { Incorporar iniciativas dos alunos relacionadas com a sua aprendizagem (atividades extra-curriculares, trabalhos } \\
\text { voluntários). }\end{array}$ & D \\
\hline Demonstrar respeito para com os alunos através das minhas atitudes em aula. & $\mathrm{C}$ \\
\hline Ser flexível no ensino ainda que isso implique desviar-me do previamente planejado. & D \\
\hline Dar sentido e significado ao conteúdo & B \\
\hline Estar preparado para trabalhar os conteúdos que vou explicar à turma. & B \\
\hline Estimular a confiança dos alunos em si mesmos. & D \\
\hline Fazer os alunos sentirem que o êxito na sua aprendizagem se deve a si mesmos e aos seus esforços. & $\mathrm{C}$ \\
\hline Dedicar tempo suficiente ao planejamento das aulas. & B \\
\hline Selecionar os recursos materiais mais adequados para cada aula & B \\
\hline
\end{tabular}

Fonte: Dados da pesquisa.

O Quadro 4 apresenta a distribuição das cargas fatoriais dos itens bloco 2, alfa de cronbach $\alpha=0,90$. Nesta análise, foi excluído o item 10 e foi contemplado as qualidades Atitudes Colaborativas (3 e 8), Insegurança ("4" e "11"), Auto Avaliação ("12" e "13") e Desenvolvimento das Competências
Docentes ("1" e "5") para o fator 2. Para o bloco 2 optou-se pelo modelo de dois fatores, aparentemente contrapondo as sugestões de Pasquali (1999) em relação ao número de itens, todavia, como esta pesquisa possui um caráter de preparação inicial de um instrumento, foi considerado mais satisfatório 
reduzir o número de itens dos dois fatores para concentrar menos qualidades psicométricas em um só item.

Quadro 4 - Matriz analítica do bloco 2 utilizando extração de dois fatores

\begin{tabular}{|c|c|c|}
\hline \multirow{2}{*}{} & \multicolumn{2}{|c|}{ Componente } \\
\cline { 2 - 3 } & $\mathbf{1}$ & $\mathbf{2}$ \\
\hline B2 1 & 0,560 & 0,472 \\
\hline B2 2 & & \\
\hline B2 324 & 0,745 & \\
\hline B2 5 & $-0,504$ & $-0,381$ \\
\hline B2 6 & 0,308 & \\
\hline B2 & & \\
\hline B2 8 & & \\
\hline B2 9 & 0,452 & \\
\hline B2 10 11 & & \\
\hline B2 12 & 0,756 & 0,835 \\
\hline B2 13 & $-0,730$ & 0,737 \\
\hline B2 14 & & \\
\hline
\end{tabular}

Fonte: Dados da pesquisa.

Neste bloco, o fator 1 (itens 2, 3, 5, e 6) tende a considerar os aspectos relacionados às atitudes colaborativas e as manifestações de Insegurança. O fator 2 (itens 1,4,7, e 8) enfatiza as qualidades de desenvolvimento de competências e a capacidade de auto avaliação (Quadro 5),

Quadro 5 - Proposta final do bloco 2 - "com que frequência costumo"

\begin{tabular}{|c|l|c|}
\hline \multicolumn{1}{|c|}{ Itens } & Fator \\
\hline 1. & Aprendi a ensinar, sobretudo, dando aulas. & B \\
\hline 2. & $\begin{array}{l}\text { As sugestões que os outros professores me } \\
\text { fazem ajudam-me a ensinar de forma mais } \\
\text { adequada. }\end{array}$ & A \\
\hline 3. & $\begin{array}{l}\text { O meu receio de agir inadequadamente afeta a } \\
\text { minha capacidade de ensinar }\end{array}$ & A \\
\hline 4. & $\begin{array}{l}\text { Desenvolvi muitas das minhas habilidades } \\
\text { docentes ensinando. }\end{array}$ & B \\
\hline 5. & $\begin{array}{l}\text { Sinto entusiasmo quando consigo ajudar um } \\
\text { aluno a aprender alguma coisa }\end{array}$ & A \\
\hline 6. & $\begin{array}{l}\text { A ideia de dar uma aula faz-me sentir nervosa } \\
\text { (o). }\end{array}$ & A \\
\hline 7. & $\begin{array}{l}\text { Cometi muitos erros didáticos, no ensino aos } \\
\text { alunos. }\end{array}$ & B \\
\hline 8. & $\begin{array}{l}\text { Com frequência obtenho, de outros } \\
\text { professores, informações úteis sobre a minha } \\
\text { própria competência como docente. }\end{array}$ & B \\
\hline
\end{tabular}

Fonte: Dados da pesquisa.

Para o bloco 3 os itens carregaram em um único fator, alfa de cronbach $\alpha=0,41$, como observado no Quadro 6.

Quadro 6 - Matriz analítica do bloco 3 utilizando um único fator

\begin{tabular}{|c|c|}
\hline & Componente \\
\hline & 1 \\
\hline B2 1 & 0,785 \\
\hline B2_2 & 0,416 \\
\hline B2_3 & $-0,547$ \\
\hline B2 4 & \\
\hline B2_5 & 0,785 \\
\hline B2 6 & 0,458 \\
\hline B2_7 & $-0,583$ \\
\hline B2 8 & \\
\hline B2 9 & 0,376 \\
\hline B2 10 & \\
\hline
\end{tabular}

Fonte: Dados da pesquisa.
Os itens do Bloco 3 estão apresentados no quadro $3 \mathrm{e}$ indicam uma abordagem bastante ampla no sentido das Competências dos professores da instituição onde é aplicado o instrumento (exceto pelo item "3", que apresenta um aspecto de exclusão da responsabilidade do professor no processo ensinoaprendizagem). Os demais itens (1, 2, 6 e 7) apontam para esta qualidade psicométrica. $\mathrm{O}$ outro aspecto que a análise semântica revelou tendência foi relacionado aos recursos materiais (8 e 10), entretanto, no item 8 menciona um aspecto institucional negativo, em relação aos recursos materiais em contraste com o item 10, onde revela um aspecto positivo deste elemento. Portanto, eliminamos o item 8 , pelos mesmos critérios do item 3 .

Quadro 7 - Proposta final da escala do Bloco 3 - Competências dos professores de uma instituição e Recursos materiais

\begin{tabular}{|c|l|c|}
\hline \multicolumn{1}{|c|}{ Itens } & Fator \\
\hline 1. & $\begin{array}{l}\text { Os professores, de uma maneira geral, são } \\
\text { capazes de ajudar a aprender, até os alunos com } \\
\text { problemas de aprendizagem }\end{array}$ & $\mathrm{A}$ \\
\hline 2. & $\begin{array}{l}\text { A maioria dos professores confia na sua } \\
\text { capacidade para motivar os alunos. }\end{array}$ & $\mathrm{A}$ \\
\hline 3. & $\begin{array}{l}\text { Se um aluno não aprende, os professores desta } \\
\text { instituição atribuem a responsabilidade ao } \\
\text { aluno. }\end{array}$ & $\mathrm{A}$ \\
\hline 4. & $\begin{array}{l}\text { Os professores dominam vários procedimentos } \\
\text { de ensino. }\end{array}$ & $\mathrm{A}$ \\
\hline 5. & $\begin{array}{l}\text { Os professores estão muito bem capacitados } \\
\text { para as disciplinas/cursos que lecionam. }\end{array}$ & $\mathrm{A}$ \\
\hline 6. & $\begin{array}{l}\text { A falta de recursos didáticos torna difícil a } \\
\text { docência. }\end{array}$ & $\mathrm{A}$ \\
\hline 7. & $\begin{array}{l}\text { Nesta instituição, a qualidade dos recursos } \\
\text { didáticos facilita o processo de ensino e } \\
\text { aprendizagem }\end{array}$ & $\mathrm{A}$ \\
\hline
\end{tabular}

Fonte: Dados da pesquisa.

Apesar do tamanho da amostra ter sido superior ao de alguns estudos semelhantes (SILVA et al., 2008; SOUZA; BRITO, 2008) o número de participantes ainda é considerado inferior ao recomendado por Pasquali (2013). Neste sentido recomenda-se estudos futuros com amostras maiores e que envolvam as diferentes regionalidades do Brasil. Mesmo preservando a identidade dos voluntários, há a possibilidade de ocorrência do fenômeno denominado por Bandura (2005) e Triola (1999) como "pressão do pesquisador", se considerarmos que as questões envolvem competência profissional. Não se sabe ao certo como os voluntários encaram este tipo de situação.

\section{Conclusão}

Conclui-se que a satisfação, a persuasão social e as experiências pregressas, são os principais responsáveis pela percepção de autoeficácia dos professores. Estes aspectos fornecem uma importante sugestão sobre as possibilidades de exploração destes fatores no que diz respeito às futuras aquisições, programas de treinamento e pesquisas futuras.

A titulação dos docentes não se mostrou muito interveniente nas percepções de autoeficácia dos voluntários da nossa pesquisa, entretanto, o tempo de docência apresentou correlação significativa na maioria dos itens da escala original. O presente estudo, com base nas análises exploratórias e 
semânticas, propõe um novo modelo de escala, formado por três blocos de itens, com objetivo de descrever os seguintes aspectos psicométricos da percepção de autoeficácia de docentes do Ensino Superior: Bloco 1: Aprendizagem e Avaliação; Conteúdo programático e Recursos didáticos; Desempenho na docência (com foco nos alunos); Auto avaliação e Relação Interpessoal (com os alunos). Bloco 2: Atitudes colaborativas e as manifestações de Insegurança; Desenvolvimento de competências e Capacidade de Auto avaliação. Bloco 3: Competências dos professores de uma instituição e Recursos materiais. Tendo em vista o modelo de escala adotado no instrumento original, em que há uma "fusão" de vários itens para duas diferentes manifestações psicométricas (a percepção de autoeficácia e a descrição da frequência de utilização) tratadas paralelamente, optamos por analisar apenas a manifestação que retrata a percepção de autoeficácia.

\section{Referências}

ACSM. American College of Sports Medicine. Position Stand: Exercise and type 2 diabetes, 2000. doi: 10.1249/ MSS.0b013e3181eeb61c.

ANDRADE, N.C.L. et al. The effects of work routine and professional satisfaction on burnout among high-school teachers. Intern. J. Human. Soc. Sci. Invent., v.6, n.4, p.50-55, 2017.

ARAÚJO, R.S.; CAVALCANTI, C.R.P.; FIGUEIREDO, E. Motivação para aprendizagem e prática musical: dois estudos no contexto do ensino superior. Área Temática: Ens. Psic. Psic. Educ. v.10, p.249-272, 2009. doi: https://doi.org/10.20396/etd. v10in.esp..944

BABBIE, E. Métodos de pesquisa de Survey. Belo Horizonte: UFMG, 1999.

BANDURA, A. Self-efficacy: toward a unifying theory of behavioral change. Psyc Rev., v.84, n.2, p.191-215, 1977. doi: http://dx.doi.org/10.1037/0033-295X.84.2.191

BANDURA, A. Guide for constructing self-efficacy scales. In: PAJARES, F. URDAN, T. Adolescence and education: v. 5. Selfefficacy and adolescence. Greenwich: Information Age, 2005. p.307-337.

BOTH, J. et al. Qualidade de vida no trabalho percebida professores de educação física. Rev. Bras. Cineantrop. Desemp. Hum., v.8, n.2, p.45-52, 2006. doi: https://doi.org/10.5007/\%25x

BZUNECK, J.A.; GUIMARÃES, S.E.R. Eficácia coletiva dos professores e implicações para o contexto educacional brasileiro. Área Temática: Ens. Psic. Psic. Educ., v.10, p.1-15, 2009. DOI: https://doi.org/10.20396/etd.v10in.esp..932.

CRONBACH, L.J. Coefficient Alpha and the Internal Structure of Tests. Psychomet. v.16, n.3, p.297-335, 1951. doi: 10.1007/ bf02310555

DANCEY, C.P.; REIDY, J. Estatística sem matemática para psicologia. Porto Alegre: Artmed Bookman, 2007.

HAIR, J.F. et al. Multivariate data analysis: with readings. São Paulo: Prentice Hall, 2003.

MARTINS C. et al. Perfil do enfermeiro e necessidades de desenvolvimento de competência profissional perfil do enfermeiro e necessidades de desenvolvimento de competência profissional. Contexto Enferm, v.15, n.3, p. 472-478, 2006. doi: http://dx.doi. org/10.1590/S0104-07072006000300012.
MENDONÇA, K.M.P.P.; GUERRA, R.O. Desenvolvimento e validação de um instrumento de medida da satisfação do paciente com a fisioterapia. Rev. Bras. Fisioter., v.11, n.5, p.369-376, 2007. doi: http://dx.doi.org/10.1590/S1413-35552007000500007

MORAES, L.C.; DURAND-BUSH, N.; SALMELA, J.H. Novos conceitos em treinamento esportivo: modelos de desenvolvimento de talentos. Brasília: INDESP. 1999.

NASCIMENTO, J.V. Escala de auto-percepção de competência profissional em Educação Física e desportos. Rev. Paul. Educ. Fís. v.13, n.1, p.5-21, 1999. doi: https://doi.org/10.11606/issn.25945904.rpef.1999.137756

PASQUALI, L. Instrumentos psicológicos: manual prático de elaboração. Brasília: IBAPP, 1999.

PASQUALI, L. Psicometria: teoria dos testes na psicologia e na educação. Petrópolis: Vozes, 2003.

PASQUALI, L. Psicometria: teoria dos testes na psicologia e na educação. São Paulo: Vozes, 2013.

PEREIRA, M.A.L.; ROCHA, M.S.; OLIVEIRA, G.A.P. Crenças de auto-eficácia de professores: localizando a produção de estudos (1977-2004). São Paulo: UNESP, 2007.

POLYDORO, S.A.J.; AZZI, R.G. Auto-regulação: aspectos introdutórios. In: BANDURA; AZZI, R.G.; POLYDORO, S.A.J. Teoria Social Cognitiva: conceitos básicos. Porto Alegre: Artmed, 2008. p.149-164

PRIETO, L.P. Las creencias de autoeficacia docente del professorado universitario. Lisboa: Faculdade de Motricidade Humana de Lisboa, 2005.

REINHOLD, H.H. Burnout. In: LIPP, M. (Org.). Stress do professor. Campinas: Papirus, 2007. p.63-78

SILVA, F.R. et al. Crenças de eficácia de professores de física e variáveis de contexto. In: ENCONTRO DE PESQUISA EM ENSINO DE FÍSICA, 2018. Curitiba. Anais... Curitiba, 2008.

SILVA, E.R.P. Perfis de gestão de sala de aula, indisciplina percebida e percepção de eficácia do professor. Braga: Universidade do Minho, 2014.

SILVA, F.L. et al. Eficácia na sala de aula: autoavaliação de professores de uma escola pública. Rev. Ensino Educ. Ciênc. Hum. v.18, n.3, p.239-243, 2017. doi: http://dx.doi.org/10.17921/2447$8733.2017 \mathrm{v} 18 \mathrm{n} 3 \mathrm{p} 239-243$

SILVA, F.L. et al. Eficácia Docente: Autoavaliação de Professores da Educação Básica. Rev. Ensino Educ. Ciênc. Hum, v.19, n.3, p. 277-282, 2018. doi: http://dx.doi.org/10.17921/24478733.2018v19n3p277-282.

SOUZA, I.F.; MENDONÇA, H. Burnout em professores universitários: impacto de percepções de justiça e comprometimento afetivo. Psic. Teoria e Pesq., v.25, n.4, p.499-508, 2009. doi: http://dx.doi.org/10.1590/S010237722009000400005 .

SOUZA, L.F.N.I; BRITO, M.R.F. Crenças de auto-eficácia, autoconceito e desempenho em matemática. Estudos de Psic., v.25, n.2, p.193-201, 2008. doi: http://dx.doi.org/10.1590/S0103166X2008000200004.

SPERBER, A.D. Translation and validation of study instruments for cross cultural research. Gastroenter., n.126, p.124-128, 2004. doi: $10.1053 /$ j.gastro.2003.10.016

THOMAS, J.R.; NELSON, J.K. SILVERMAN, S.J. Métodos de pesquisa em atividade física. Porto Alegre: Artmed, 2007.

TRIOLA, M.F. Introdução à estatística. Rio de Janeiro: LTC, 1999. 